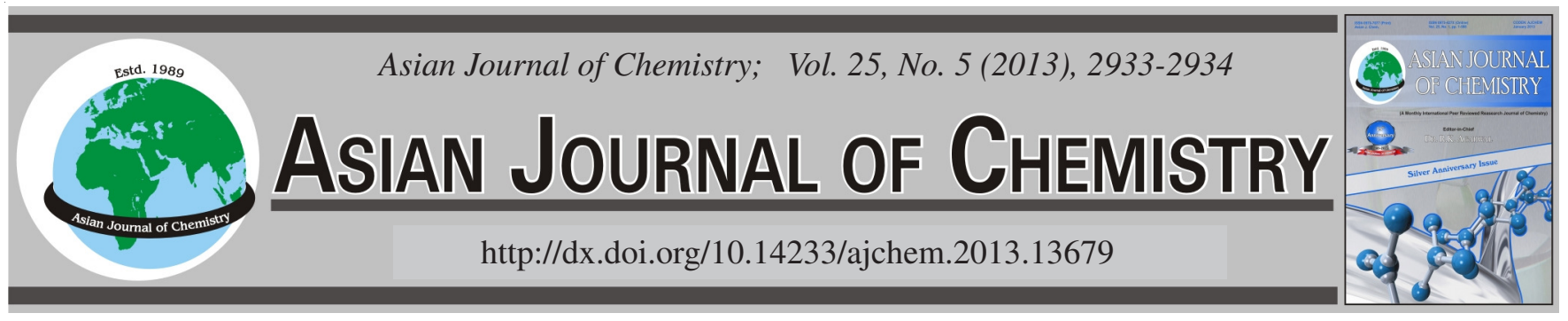

NOTE

\title{
Determination of Xylenol Orange Based on Chemical Oscillating Reaction Catalyzed by a Macrocyclic Complex
}

\author{
Lin $\mathrm{Hu}^{1}$, JiHUI $\mathrm{HE}^{2}$ and GANG Hu${ }^{2, *}$
}

${ }^{1}$ Institute of Applied Chemistry, East China Jiaotong University, Nanchang 330013, P.R. China

${ }^{2}$ Department of Chemistry, Anhui University, Hefei 230039, P.R. China

*Corresponding author: E-mail: hugky@21cn.com; hulin21@hotmail.com

(Received: 29 February 2012;

Accepted: 30 November 2012)

AJC-12486

\begin{abstract}
A new analytical method for the determination of xylenol orange based on the oscillating system is proposed. The oscillating system involves a macrocyclic complex $[\mathrm{CuL}]\left(\mathrm{ClO}_{4}\right)_{2}$ as catalyst, malic acid as organic substrate and sodium bromate as oxidant. The ligand $\mathrm{L}$ in the complex is 5,7,7,12,14,14-hexamethyl-1,4,8,11-tetraazacyclotetradeca-4,11-diene. The experimental results show that, when the system is perturbed by adding variable amounts of xylenol orange, the change of the oscillation amplitude is linearly proportional to the concentration of logarithm of the xylenol orange in the range $2.5 \times 10^{-7}-2.5 \times 10^{-4} \mathrm{M}$. Hence, an array of xylenol orange involving its perturbation effects on a Belousov-Zhabotinsky system has been established.
\end{abstract}

Key Words: Chemical oscillating reaction, Xylenol orange, Determination, Macrocyclic complex.

ᄂ - - - - - - - - - - - - - - - - - - - - - - - - - - - - - - - - - -

Chemical oscillating reaction, which exhibits periodic changes in concentration of some species (usually a reaction intermediate), occurs only in the non-equilibrium systems ${ }^{1}$. A Belousov-Zhabotinsky (BZ) reaction reaction, one of the most famous examples of chemical oscillations, has been studied owing to its unique kinetic non-equilibrium feature ${ }^{2-4}$. These kinetic features have made such system potentially useful in the analytical chemistry field and some methods for determinations of analytes based on their perturbation effects on Belousov-Zhabotinsky reaction have been reported. These analytes include $\mathrm{Ag}^{+}$ion $^{5},\left[\mathrm{Fe}(\mathrm{CN})_{6}\right]^{3-}$ or $\left[\mathrm{Fe}(\mathrm{CN})_{6}\right]^{4-}$ ion $^{6}$, hydroquinone ${ }^{7}$ and vitamin $\mathrm{C}^{8}$.

Oscillating reactions catalyzed by macrocyclic complex of $\mathrm{Cu}$ (II) or $\mathrm{Ni}$ (II) were first discovered by Yatismirskii and Tikhonova ${ }^{9}$. Recently, we have reported series of macrocyclic complex-catalyzed oscillating systems ${ }^{10-13}$. We have studied unique features of a macrocyclic complex-catalyzed oscillating system ${ }^{10}: \mathrm{NaBrO}_{3}-\mathrm{H}_{2} \mathrm{SO}_{4}$-malic acid-[CuL] $\left(\mathrm{ClO}_{4}\right)_{2}$, where the ligand $\mathrm{L}$ in the complex $[\mathrm{CuL}]\left(\mathrm{ClO}_{4}\right)_{2}$ is $5,7,7,12,14,14-$ hexamethyl-1,4,8,11-tetraazacyclotetradeca-4,11-diene. We have also used this $[\mathrm{CuL}]\left(\mathrm{ClO}_{4}\right)^{2-}$ catalyzed oscillating system for kinetic determination of $\mathrm{Ag}^{+14}$, pyrogallol ${ }^{15}$, calcium pantothenate ${ }^{16}$, Alizarin red $\mathrm{S}^{17}$ and catechol ${ }^{18}$. In this notes, we have surveyed the effect of xylenol orange perturbation on this novel Belousov-Zhabotinsky system.
The catalyst $[\mathrm{CuL}]\left(\mathrm{ClO}_{4}\right)_{2}$ was prepared according to literature methods ${ }^{14,19,20}$ and was identified by IR spectra and elemental analysis. All chemicals used were of analytical reagent grade. Solutions of $0.6 \mathrm{M} \mathrm{NaBrO}_{3}, 2 \mathrm{M}$ malic acid, $0.0221 \mathrm{M}[\mathrm{CuL}]\left(\mathrm{ClO}_{4}\right)_{2}$ were prepared in $1.15 \mathrm{M}$ sulfuric acid. Solutions of $0.01 \mathrm{M}$ xylenol orange were made immediately before the experiment. Solutions with lower concentrations were prepared prior to use. Double distilled water was used in all cases.

The oscillating reaction experiments were conducted by the methods as described previously ${ }^{15,18}$. The perturbation experiments were carried out by injecting $0.2 \mathrm{~mL}$ of sample containing variable amounts of xylenol orange to oscillating system in steady state, causing the amplitude to increase sharply. Thus, changes of oscillating amplitude $\Delta \mathrm{A}=\mathrm{A}-\mathrm{A}_{0}$ $\left(\mathrm{A}_{0}\right.$ and $\mathrm{A}$ are the oscillation amplitude before and after the injection, respectively) were used as parameter to determine xylenol orange (Fig. 1).

We performed perturbation experiments under the following conditions: $\left[\mathrm{NaBrO}_{3}\right]=0.015 \mathrm{M}$; [ malic acid $]=0.2$ $\mathrm{M} ;\left[\mathrm{H}_{2} \mathrm{SO}_{4}\right]=1.15 \mathrm{M}$; $[\mathrm{CuL}]\left(\mathrm{ClO}_{4}\right)_{2}=2.65 \times 10^{-3} \mathrm{M}$. The response to the xylenol orange perturbation was obtained by employing changes in oscillation amplitude $(\Delta \mathrm{A})$ versus different concentrations of xylenol orange. The change in oscillation amplitude $(\Delta \mathrm{A})$ obtained is linearly proportional 

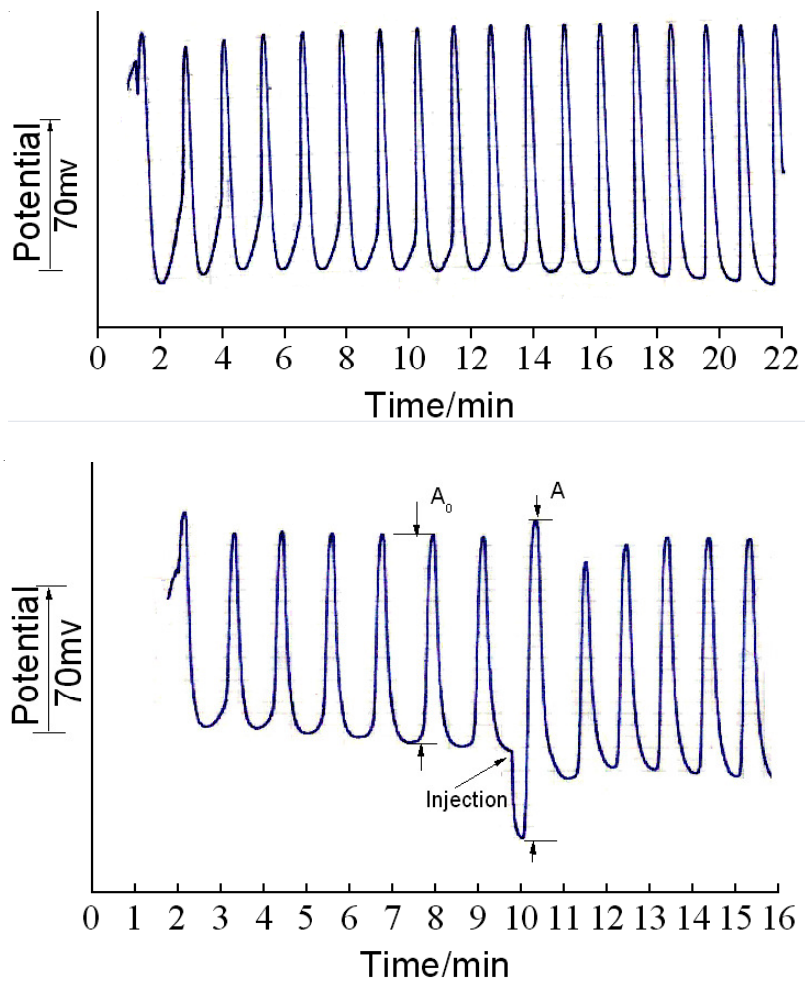

Fig. 1. Typical oscillation profiles for the proposed oscillation system in the absence and presence of variable amounts of xylenol orange perturbation using platinum electrode: (a) [Xylenol orange $]=0.000$ $\mathrm{M}$, (b) [xylenol orange $]=5.0 \times 10^{-5} \mathrm{M}$. Common conditions: $\left[\mathrm{NaBrO}_{3}\right]=0.015 \mathrm{M} ;[$ malic acid $]=0.2 \mathrm{M} ;\left[\mathrm{H}_{2} \mathrm{SO}_{4}\right]=1.15 \mathrm{M}$; $[\mathrm{CuL}]\left(\mathrm{ClO}_{4}\right)_{2}=2.65 \times 10^{-3} \mathrm{M}$

to the logarithm of the xylenol orange concentration over the range of $2.5 \times 10^{-7}-2.5 \times 10^{-4} \mathrm{M}$ (Fig. 2). The calibration data obtained obey the following linear regression equation:

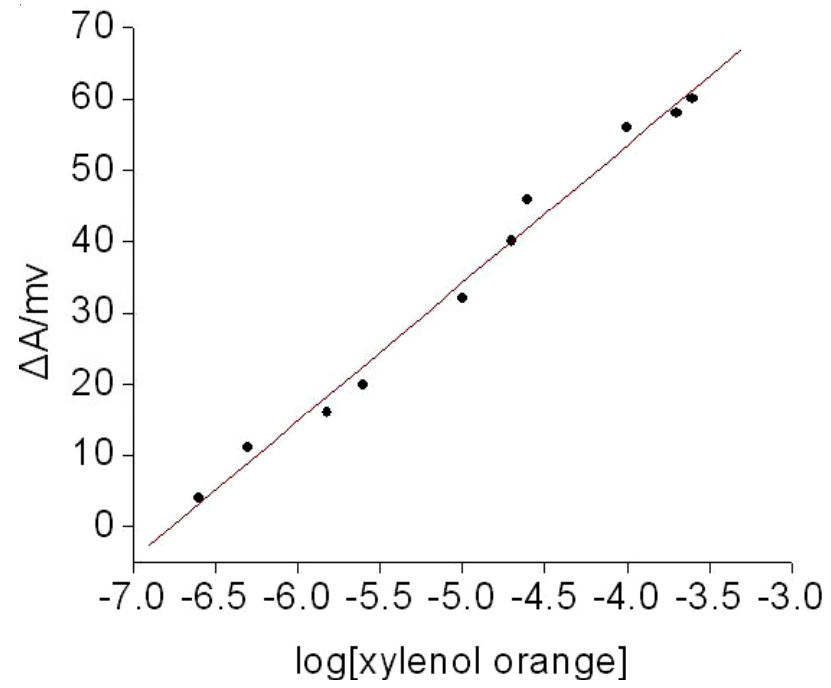

Fig. 2. Calibration curve of the increase in amplitude versus the logarithm of [xylenol orange] in the range of $2.5 \times 10^{-7}-2.5 \times 10^{-4} \mathrm{M}$. Common conditions: $\left[\mathrm{NaBrO}_{3}\right]=0.015 \mathrm{M}$; $[$ malic acid $]=0.2 \mathrm{M} ;\left[\mathrm{H}_{2} \mathrm{SO}_{4}\right]=$ $1.15 \mathrm{M} ;[\mathrm{CuL}]\left(\mathrm{ClO}_{4}\right)_{2}=2.65 \times 10^{-3} \mathrm{M}$

$$
\begin{aligned}
& \Delta \mathrm{A}=130.96+19.34 \log [\text { xylenol orange }] \\
& (\mathrm{R}=0.99388, \mathrm{~N}=10)
\end{aligned}
$$

The precision (RSD), calculated from five perturbations of $5.0 \times 10^{-5} \mathrm{M}$ xylenol orange, was $4.3 \%$. The detection limit obtained is $1.3 \times 10^{-7} \mathrm{M}$. Such a precision is quite acceptable.

Table- 1 shows the effects of some foreign species on the determination. It is found that $\mathrm{Ag}^{+}, \mathrm{Cl}^{-}, \mathrm{Mn}^{2+}, \mathrm{I}^{-}$and $\mathrm{NO}_{2}$ have serious interference. $\mathrm{Ca}^{2+}, \mathrm{Mg}^{2+}, \mathrm{Al}^{3+}, \mathrm{Ni}^{2+}$ and $\mathrm{Li}^{+}$show no interference on determination. The results are acceptably selective.

\begin{tabular}{cc} 
TABLE-1 \\
EFFECTS OF THE SOME FOREIGN SPECIES \\
\hline Foreign ions and species & Tolerated ratio \\
\hline $\mathrm{Ca}^{2+}, \mathrm{Mg}^{2+}, \mathrm{Al}^{3+}$ & 1300 \\
$\mathrm{Ni}^{2+}, \mathrm{Li}^{+}$ & 100 \\
$\mathrm{Fe}^{3+}, \mathrm{Zn}^{2+}$ & 10 \\
Glucose, phenol, $\mathrm{F}^{-}, \mathrm{OAc}^{-}, \mathrm{Cu}^{2+}$ & 1 \\
$\mathrm{Ag}^{+}$ & 0.5 \\
$\mathrm{Cl}^{-}$ & 0.1 \\
$\mathrm{Mn}^{2+}$ & 0.05 \\
$\mathrm{I}^{-}, \mathrm{NO}_{2}^{-}$ & 0.01 \\
\hline
\end{tabular}

\section{ACKNOWLEDGEMENTS}

The authors gratefully acknowledged the financial funding of this work by the National Science Foundation of China (Nos. 21171002, 31160187).

\section{REFERENCES}

1. R.J. Field and M. Burger, Oscillations and Traveling Waves in Chemical Systems, Wiley, New York (1985).

2. V.P. Kazakov, A.D. Karavaev and S.R. Vakhidova, React. Kinet. Catal. Lett., 45, 99 (1999).

3. H. Pekkuz, I. Uzun and Z.F. Gu, Biol. Technol., 99, 2009 (2007).

4. T. Turek, Catal. Today, 105, 275 (2005).

5. J.B. Raoof, R. Ojani and A. Kiani, Anal. Sci., 20, 883 (2004).

6. M. Jiang, Y. Li, X. Zhou, Z. Zhao, H. Wang and J. Mo, Anal. Chim. Acta, 236, 411 (1990).

7. J. Gao, J. Ren, W. Yang, X. Liu, H. Yang, Q. Li and H. Deng, J. Electroanal. Chem., 520, 157 (2002).

8. J. Gao, H. Yang, X. Liu, J. Ren, X. Lu, J. Hou and J. Kang, Tananta, 55, 99 (2001).

9. K.B. Yatismirskii and L.P. Tikhonova, Coord. Chem. Rev., 63, 241 (1985).

10. G. Hu, Z. Zhang, L. Hu and J. Song, Transtion Met. Chem., 30, 856 (2005).

11. G. Hu and Z. Zhang, Chem. Lett., 35, 1154 (2006).

12. G. Hu, L. Hu, S. Ni and Z. Zhang, React. Kinet. Catal. Lett., 88, 349 (2006).

13. G. Hu, Z. Xu, F. Xie, L. Hu and S. Ni, Asian J. Chem., 13, 137 (2001).

14. L. Hu, G. Hu and H. Xu, J. Anal. Chem., 61, 1021 (2006).

15. G. Hu, P. Chen, W. Wang, L. Hu, J. Song L. Qiu and J. Song, Electrochim. Acta, 52, 7996 (2007).

16. L. Chen, G. Hu, J. Zhang and L. Hu, Mendeleev Commun., 19, 224 (2009).

17. G. Hu, L. Chen, J. Zhang, P. Chen, W. Wang, J. Song, L. Qiu, J. Song and L. Hu, Central Eur. J. Chem., 3, 291 (2009)

18. P. Chen, G. Hu, W. Wang, J. Song, L. Qiu, H. Wang, L. Chen, J. Zhang and L. Hu, J. Appl. Electrochem., 38, 1779 (2008).

19. N.F. Curtis and R.W. Hay, J. Chem. Soc. Chem. Commun., 534 (1966).

20. D.A. House and N.F. Curtis, J. Am. Chem. Soc., 86, 223 (1964). 